\title{
The Spatial Self: Location-Based Identity Performance on Social Media
}

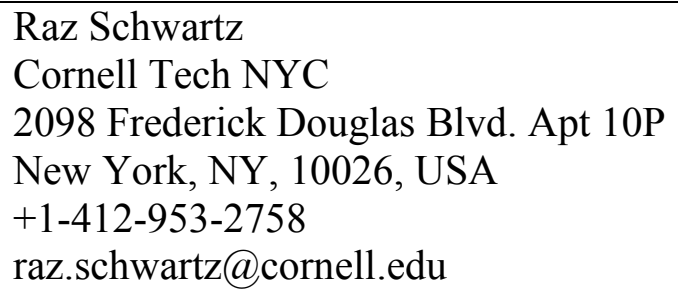

\author{
Germaine R. Halegoua \\ Film and Media Studies Department \\ 225 Oldfather Studios \\ 1621 W. 9th St. \\ Lawrence, KS 66044, USA \\ $+1-785-864-1931$ \\ grhalegoua@ku.edu
}

No lead author. Both authors made equal contributions to this paper.

Raz Schwartz is a postdoctoral researcher at Cornell Tech NYC and a Magic grant fellow at the Brown Institute for Media Innovation at Columbia Journalism School. Raz studies social media usage in urban settings and focuses on examining local social interactions by applying computational social science methods. Prior to joining Cornell Tech NYC, Raz was a postdoctoral researcher at the Social Media Information Lab at Rutgers University. Raz completed his Ph.D. in the STS program at Bar-Ilan University and was a visiting scholar in the Human Computer Interaction Institute at Carnegie Mellon University. His research was presented in various prestigious academic settings and was featured in media outlets such as the Wall Street Journal, Wired, Rhizome, and The Atlantic.

Germaine R. Halegoua is an Assistant Professor in the Film and Media Studies Department at the University of Kansas. She received her $\mathrm{PhD}$ from the Media and Cultural Studies program at the University of Wisconsin - Madison. Her research interests focus on relationships between urban environments and digital media, social media and location, power relations and emerging technologies, and cultural geographies of digital media.

Abstract: As a growing number of social media platforms now include location information from their users, researchers are confronted with new online representations of individuals, social networks and the places they inhabit. To better understand these representations and their implications, we introduce the concept of the "spatial self": a theoretical framework encapsulating the process of online self-presentation based on the display of offline physical activities. Building on previous studies in social science, humanities, computer and information science, we analyze the ways offline experiences are harnessed and performed online. We first provide an encompassing interdisciplinary survey of research that investigates the relationships between location, information technology, and identity performance. Then we identify and characterize the spatial self as well as examine its occurrences through three case studies of popular social media sites: Instagram, Facebook, and Foursquare. Finally, we offer possible research directions and methodological considerations for the analysis of geocoded social media data.

Keywords: spatial self, location-based social media, social media, identity, performance, Foursquare, Instagram, Facebook 


\section{Introduction}

As the incorporation of geocoded information into text, images and video on social media platforms continues to grow, so do the norms, practices, and meanings that surround these digital-physical traces. Public officials, urban planners, technology developers, and researchers have begun to gather and analyze geo-tagged photos and videos, status updates, and location-announcements in order make claims about the use and design of public space, urban infrastructure, mobility patterns, local sentiment, and experiences of place. These efforts raise many questions about the use of location-based social media and the representation and documentation of physical mobility and physical presence that are in need of further investigation. For example, what can we learn about users from the growing number of visualizations of their physical activity on social media? What are the intentions, conditions, and situations under which these digital traces are produced and understood? How do these geocoded data inform our understanding of mobility, the meaning of physical place, and identity performance that occurs via location-based social media? This paper is an effort toward answering these questions and understanding how people harness locationbased technologies in order to represent themselves through social media.

We recognize the display of physical activities on social media as particular expressions of the "spatial self." The spatial self refers to a variety of instances (both online and offline) where individuals document, archive and display their experience and/or mobility within space and place in order to represent or perform aspects of their identity to others. We focus on a particular articulation of the spatial self, one that is performed through digital applications that record activities and experiences in physical places, which can be shared 
with others via social media. In other words, the way we present ourselves to our online audiences is no longer only by textual and visual cues such as status messages, photos or videos but also through geocoded digital traces, geographical data visualizations, and maps of individual patterns of mobility.

To introduce the concept of the spatial self, we build on previous studies in social science, humanities, information and computer science as well as previous theories of online and offline identity and self-presentation, critical and feminist geography, and presentations of place on social media. This paper reviews these studies and unites them through the concept and characteristics of the spatial self. In order to introduce this concept, we will focus on three case studies that illustrate different online performances of the spatial self. First, we examine Instagram and the way participants' photos are presented and plotted in relation to geographic locations. Second, we describe the use of geo-tagged data and mapping tools on Facebook. Finally, we trace the various affordances of Foursquare in regard to physical activity sharing practices.

By considering geocoded practices on social media as part of the spatial self, this paper offers three main contributions. First, we provide an interdisciplinary survey of works that study the relationships between location, information technology, and social identity. Second, we introduce and discuss the characteristics and potential applications of the spatial self. We extend current discussions of the socially-driven, performative aspects of location announcement in order to present the spatial self as a theoretical framework for making sense of practices of location announcement and expressions of place online. In addition to recognizing the spatial self as a theoretical lens, we also suggest the spatial self 
as a critical way to revisit the increasingly voracious collection of location-based data, and to reevaluate the geocoded traces that become data, in terms of their social functions, intentions, contexts, and situations under which they are produced.

\section{Identity, Place, and Social Media}

Studies concerning practices of self-presentation and impression management on popular social networking sites have increased significantly in recent years. As Hogan (2010) observes, Goffman's theories regarding identity and self-presentation, "front stage" and "back stage" presentations, and a focus on situations, contexts, and audiences for social behavior have been incredibly prevalent in social media literature. Additionally, Butler's notion of performativity has been utilized in discussions of mobility and subjectivity (Gregson and Rose, 2000) as well as collocated online representation and sharing. For example, Van House (2009) analyzed how both Goffman and Butler's interpretations of performance apply directly to mobile photography and concluded that by taking and posing for photographs we enact identities and manage impressions of ourselves, both individually and collectively. Overall, scholars tend to agree that through images, video, status updates, profiles, friend lists, visible conversations, tastes and interests, and comments that appear within their profile, social media participants present a highly curated version of themselves (Mendelson and Papacharissi, 2010).

However, studies concerning the combination of social media or location-based social media, identity performance, and place are still rare. Previous work has discussed the interfacing of these elements in terms of the diverse physical locations of members of virtual communities, or identity formation and performance in relation to online and offline 
spaces (Goodings et al., 2007). Sutko and de Souza e Silva (2011) introduce the "presentation of place" in order to explain the performance of identity via location-aware technologies. However, "presentation of place" tends to focus on the impressions of a physical place provided by its visitors, or the social construction of place through locationbased social media, rather than the harnessing of place to perform identity to a social network. de Souza e Silva and Frith (2012) expand on this concept by arguing that the "presentation of location (not only places)" might encourage homophily, bonding, and trust among those who frequent certain locations and participate in location-based social media.

\section{Location-based Social Media and the Self}

In the years preceding the pervasiveness of location-based social media platforms, feminist geographer Mei-Po Kwan (2002) suggested that geocoded digital traces such as photographs, audio, and video clips can be gathered and analyzed in order to access the complexities and local knowledges of mobility and urban experience. She notes that studies like these can lead to qualitative rather than exclusively quantitative analysis utilizing GIS. More specifically, Kwan and others (Alibrandi et al., 2000) have noted the value of geocoded digital expressions in creating "life maps," "body inscriptions," "spatial stories," or "biographical accounts" of everyday life from specific demographic and cultural perspectives. Locative media projects from the early 2000s explicitly encouraged the use of mobile technologies in this way. Farman (2012) analyzes these platforms as "interfaces of re-membering," or means to create and disseminate embodied individual and community histories of place. 
Locative media applications focused primarily on location-announcement (such as Dodgeball, Google Latitude, BrightKite, Foursquare, Loopt) have been analyzed through a slightly different lens. Instead of representations of personal histories of place, spatial stories, or body inscriptions, scholars have noted the ways in which these applications promote new relationships between physical and digital spaces, local information, spatial and social relations, and feelings of presence and proximity. Terms such as "net locality" (Gordon and de Souza e Silva, 2011) and "hybrid mediated spatiality" (Sheller, 2012) have been used to describe the overlay of physical space, digital information, socio-spatial relations and contexts that occur through these mobile applications. The game mechanics integrated into location-based services like Foursquare and Gowalla have been understood to render sociality and place into a networked game (Hjorth et al., 2012) or to turn "life into a game" by encouraging participants to alter mobility patterns based on game-based rewards (Frith, 2013).

Moreover, studies have shown that diverse motivations and contexts for location announcement over social networks lead to socially-driven decisions about disclosure or non-disclosure of location. de Souza e Silva and Frith (2012) note that although locationbased social media have been promoted in terms of coordination or meeting up with other users in physical space, many users choose to selectively broadcast their location even when there is limited or no possibility for a face-to-face meeting. Humphreys (2012) suggests that practices of cataloging and archiving personal mobility and presence within place encourage intimate bonding with friends, are used in the service of bragging or "showing off", self-promotion, making inside jokes, recording places as a memory aid, or receiving points or rewards for particular habits or actions. Location-based social media 
users often understand their participation in location-announcement as augmenting or reinforcing other online profiles (Frith, 2012; Humphreys, 2007; Patil et al., 2012). In all of these instances, the personal narratives and individual representations of physical mobility on social media undoubtedly omit certain locations, emphasize others, and reveal traces of mobility which are calculated but imprecise.

Larissa Hjorth notes the playful, creative, and diverse social practices that emerge on these platforms (Hjorth, 2013). As Barkhuus et al. (2008) observed, expressing "where you are" over a social network does not solely inform others of your location, but may also signal mood, lifestyle, or life events and maintain or support intimate social relationships. The manner in which certain locations or activities are named, captioned, or annotated can be understood as performative. Cramer et al. (2011) provide evidence for this claim in their study of Foursquare users and the common practice of creating "imaginary" places, and fictitious or creative names for places or events. Relatedly, Sheller (2013) has noted that several mobile media artists and activists have attempted to override the commercial and surveillance aspects of mobile technologies and platforms and to create creative and "disruptive spaces of resistance, of sharing, and of convivial publics" and "serendipitous play".

We agree with the aforementioned scholars in that we recognize the diversity of practices circulating within mobile social media and location-based systems. We present the concept of the spatial self as an effort to identify and examine the ways in which individual and collective agency is routinely enacted by participants within these systems. Building on previous and ongoing research, this paper considers expressions of the spatial self as 
performance in addition to play, equating the spatial self more along the lines of selfpresentation, ontology, and identity production rather than coordination, ludology, or creative misuse.

In the following section, we introduce the concept of the spatial self as a lens through which to read the myriad expressions and performances of identity and place online via social media. As our case studies will illustrate, there is ample opportunity to produce and share the spatial self over these platforms, and this is regularly done. However, these visualizations of mobility and "presentation of place" are not always read in accordance with identity formation and exhibition. In subsequent sections we will discuss what can be gained from doing so.

\section{The Spatial Self}

Previous and ongoing research about identity, place, and social media is the foundation for the spatial self - a theoretical framework that explores the presentation of the self, based on geographic traces of physical activity. The spatial self might be a novel term, but it is not a new concept. We employ the "spatial self" to refer to a variety of instances (both online and offline) where individuals document, archive and display their experience and/or mobility within space and place in order to represent or perform aspects of their identity to others. These are historically rooted practices that combine lived and/or imagined social and spatial realities in order to express identity and socio-spatial position.

Pre-digital examples of the spatial self abound. Diaries of urban flaneurs, maintained as early as the Victorian era, not only archive individual physical movement through urban 
environments, but also document social and cultural change and serve as a window into relationships between social class, gender dynamics, public and private spaces and the city (Wilson, 1992). The curated photo album, slideshow, or home video footage that documents vacations or personal moments and might have been put on display or shown to friends and family members are expressions of where someone was located both socially and spatially (Walker and Moulton, 1989). Postcards with photographs of distant locales or familiar places, annotated by the sender, articulate something social and spatial about presence at particular moments in time (Milne, 2010).

Digital expressions of the spatial self are becoming increasingly embedded in our spatial practices and the social production of space. As millions of people use these tools to annotate their physical locations and instantly share them with various social groups such as "friends" and "followers," the spatial self is becoming a prominent part of our daily life. However, the spatial self is not merely a byproduct of mobile social media use, nor is it simply an aggregation of geo-coded data. The spatial self refers to intentional socio-cultural practices of self-presentation that result in dynamic, curated, sometimes idealized performances of who a user is, based on where they go.

Unlike hand drawn maps requested by researchers, check-ins and images produced over location-based social media are embedded with layered significations and social signals that are produced for pre-selected audiences (as well as unintended audiences in some cases), under various contexts, and for different reasons. In this paper we suggest that through social networks like Instagram, Foursquare, and Facebook, participants present the 
spatial self without explicitly being invited to do so, in more "organic" circumstances than via directed research studies.

The spatial self on social media portrays similar characteristics to other instances of online self-representation. As Papacharissi notes, through social media an individual "gains access to a variety of multimedia tools that enable the possibility for more controlled and more imaginative performances of identity online. .." (Papacharissi 2011: 307). Building on this understanding of identity performance and social media, we consider digital expressions of the spatial self to be a particular type of "networked self," one that primarily relies on the curation of representations of physical place and mobility to perform identity online. As is the case with other types of self-presentation, the spatial self is enacted in both synchronous and asynchronous online environments and may be coordinated across a variety of platforms. As Hogan (2010) notes, self-presentation practices on social media can be split into performances, which take place in synchronous "situations" and artifacts that take place in asynchronous "exhibitions." This distinction also applies to locative media practices as users are both sharing their location with others in real time as well as archiving these physical actions which are then aggregated and presented in various forms such as dots on a map or summarized statistics.

A common feature across digital platforms is that when a user signals their location, a builtin mechanism notifies other nearby friends of the current location of the user. This synchronous notification system encourages users to perform their offline experience in real time. In this way, the real-time synchronous nature of this social interaction takes on different meanings throughout various days of the week and times of the day. The 
significance of real-time sharing disappears when we look at the exhibition aspects of the spatial self. When aggregating users physical actions and location data over time, the subtleties of the temporal nature of these actions are removed in favor of artifacts such as maps and infographics that showcase an aggregated representation of the user's entire historical online-offline actions.

Much like many other online identity practices on social networks, the spatial self is based on a highly curated depiction of the individual. Users of these services do not share every offline, physical action with their online social circles, but carefully choose the places and times when these actions are broadcast. Drawing on the theoretical frameworks of identity performance put forth by Goffman and Butler, we recognize the spatial self as a practice of identity performance that is constituted over time through "a stylized repetition of acts" (Butler 1988: 519). In this case, the spatial self relies on a stylized repetition of presenting certain places, with certain connotations and meanings, as constitutive of one's identity performance. By curating their experiences, people share only a portion of their daily life, mostly focusing on physical locations that can shape others' perceptions of who they are and where they go, or places and events that they select to archive over time.

Frith (2012) observes that these curated performances regularly occur via location-based social media and categorizes some of these practices as "presenting an idealized self to others" and "the presentation of the present self to the future self". In this way, visits to mundane, intimate, embarrassing, or private venues might not be considered venues worth sharing while more social or public venues, or venues that have shared meaning for an individual's social network or specific significance for an individual, will appear more 
prominently in these online actions. As such, users select which kind of places they would like to associate with their constructed "social identity" online and utilize their social identity "to construct a performance that will allow them to negotiate social situations" (boyd, 2002: 22). Therefore, the traces that manifest on these systems are usually filtered, choreographed displays of mobility and experiences of place that play a significant role in identity performance as well as sociability: they are not absolute or precise but abstracted, symbolic, and performative.

The spatial self is shaped by the character of a physical place and the ways users associate themselves with physical place. The character of a place is a social construct that is continuously created and adjusted by the plethora of visitors to that location and the connotation of that place. When a user chooses to broadcast their location in relation to a specific venue, they are relating themselves with the values and social groups that are represented by that specific physical place. In this way, users are building their online identity through attaching themselves to the specific narrative of a physical place (Schwartz, forthcoming 2014). This combination of "private geographies," or geographies that have shared meaning among an intimate group (Brown et al., 2007), wider social connotations and understandings of particular places, and the selection of particular places to be added to ones online profile combine to produce the representations of the spatial self.

Moreover, like other aspects of our identities, the spatial self is not a unique, singular representation but rather a multifaceted and fragmented depiction of the self that has many different versions, each with its own characteristics and targeted audience (Van 
Zoonen 2013). Its representations are therefore messy, sometimes even contradictory, as people commonly perform more than one spatial self in different situations or contexts, at different times, and to different audiences. As different social networks cater to users' interaction with various social groups or audiences, each user can create several distinct depictions of their physical activity, taking into consideration how each platform will showcase their actions and how audiences will interpret them. A user's geo-tagged activity on a certain platform such as Facebook can differ from their activity on other platforms such as Foursquare and Instagram.

These digital traces can be read as new styles of inscribing the body within digital and physical socio-cultural environments, revealing fragments of larger ontological stories about space, place, and embodied mobility. As Grosz (1992) and Farman (2012) recognize, both bodies and stories inscribe themselves (and each other) within space and place, and are inscribed by their environments. The spatial self is constituted from a bricolage of personal and collective, private and public meanings and narratives of place.

Finally, although the spatial self is constructed by many small, recorded actions at the coffee shop, the bar, the park, or the movie theater, it is often experienced by the audience as an aggregated representation. The spatial self is therefore the result of computational processes, social and physical practices that "connect the dots" and produce a depiction, often in the form of a map or networked visualization, that conveys the user's archive or catalog of broadcasted physical actions. The images on Instagram Photo Map, the distance between and locations represented in Foursquare check-ins, the place markers on Facebook and Twitter applications are not merely lines on a map but a "mapping of bodies onto 
space-time that emanates from their pre-discursive practices of everyday life" (Kwan, 2002: 653).

\section{CASE STUDIES}

In the following section we will examine the expressions of the spatial self on popular, mainstream social networking platforms where geocoded digital traces are routinely produced as part of users' everyday activities. Each of these platforms is somewhat different in terms of intended use and technological system. While we do not offer a direct analysis of these platforms and practices, we identify certain technological and social affordances that enable the performance and expression of the spatial self and social practices that might be reinterpreted in terms of the spatial self. We focus on three categories of social media platforms that exhibit three distinct ways of representing the spatial self via social media: photographic, mixed use, and location-based social media networks. (As new platforms, design innovations, online communities, and social norms emerge within pre-existing social media services these categories will undoubtedly change.) For each platform and category we will present descriptions of the platform and its affordances, as well as examples of actual use that have been documented in other research. In the subsequent section we will utilize these descriptions and examples in order to present potential themes and questions that may be interrogated through the framework of the spatial self.

\section{Photographic Social Networks}


A current trend in social media and location-based services is the production of geocoded photographs that represent images of particular locations and the events that take place within these locations, that are then shared with a social network or more public audience. More recently, several photographic locative media services have also added video, and a few geocoded video-sharing services have been launched. The location-based social media categorized as "photographic" in this paper, utilize photography as the primary mode of expressing the spatial self. These platforms are centered around the creation, exhibition, and sharing of geocoded photographic images and highlight the camera as the primary tool needed in order to participate on these platforms.

Instagram is a mobile photo-sharing social network that offers its users the ability to take photos directly from their mobile phone and instantly share them with friends as well as the general public. The application was first launched in October 2010 and has a reported user base of more than 150 million international subscribers (Instagram, 2013). Recording the physical location where the photos were taken is a fundamental part of the platform. Photographs that are uploaded and shared on the user's "Photo Map" contain the exact longitude and latitude coordinates of the photo. Users can also choose to tag an image to a specific venue from of a list of nearby venues presented to them during the publishing process. The location is then displayed to other users in a timeline or news feed where participants can view photos taken by the users they follow.

As users upload more and more photos, their Photo Maps are augmented, showcasing their activity in various physical locations around the world. Other Instagram users can view these maps through the individual user's profile page. Users can also "drill down" using 
this interactive map and study the various places a user has taken photographs, down to street level specificity. In this way, local and individual patterns of mobility can be visualized and archived as well.

By utilizing Instagram's API, recent works have tried to make sense of the massive collections of photographic representations on Instagram (Hochman and Manovich, 2013; Hochman and Schwartz, 2012). While studies that focus on methods for analysis of geolocated photographic images (Crandall et al., 2009) or studies that utilize geocoded photographs to make claims about urban space (Doersch et al., 2012) have gained traction, scholars are still investigating questions pertaining to motivations for use and social practices and norms on Instagram.

\section{Mixed Use Social Networks}

We consider social networking sites such as Facebook and Twitter to fall into the category of "mixed use social networks." These sites do not rely primarily on locationannouncement or photographic representation in order to function. Instead, these platforms employ a variety of modes of communication (rather than a primary type of functionality) in order to connect with members of a social network and often combine photography, video, text, links, graphics, and location announcement within individual profiles. These platforms most closely illustrate Ellison and boyd's definition of a social networking site (SNS) (Ellison and boyd, 2013).

Following the growing popularity of check-in services and the rapid growth of companies like Foursquare and Gowalla, Facebook and Twitter began to offer users similar location 
announcement functionality on their platforms. In addition to posting a status update or uploading a photo or video or link, Facebook mobile application users have the option to check-in to a physical venue. The check-in action is then displayed to the user's friends via timeline or through a mobile notification, similar to a status update. Users can also checkin to places and tag friends who are collocated with them. In this way, the check-in action is augmented with some social context indicating to other friends in the user's network the situation under which the user is experiencing that specific location. These check-ins are then aggregated and appear on the user's account as a significant part of their profile timeline. If enabled by the user, their account has an additional tab named "Map" that plots the users' check-ins numerically on a world map (Figure 2). Similar to Instagram's Photo Map, users can zoom in and examine an individual's check-ins based in their geographical clustering. Facebook imagines this location functionality as an archive of past, present, and future personal mobility (Cox, 2011).

Facebook data scientists have conducted a few studies on the demographics of participants who utilize the check-in function, including information about where, and when they check in. Facebook researchers were able to visualize popular vacation routes, ages and political affiliations of check-in users, and check-in activity in Midtown Manhattan during a typical workweek (Moore, 2012). However, researchers have yet to address motivations for using the Facebook check-in function or identify how location-announcement via mixed use social media platforms is read and understood by participants and audiences.

\section{Location-based social media}


Foursquare is a location-based social network that was first launched in March of 2009 and offered participants a way to "check-in" to the places they visit and instantly share that information with their friends. In January 2013 the company reported that the service had garnered over 30 million users worldwide, making it one of the largest location-based services in the world (Foursquare, 2013). Every day, millions of users share their checkins with friends and explore new places in their local surroundings as the application is designed to encourage the sharing of local knowledge as well as finding out where your friends are located.

In addition to venue recommendations and tips, Foursquare offers discounts and rewards for certain check-in behaviors. While Foursquare's gaming elements have been recognized as a popular use of the system, studies about Foursquare use have also revealed that participants are sometimes concerned about acquiring virtual rewards such as mayorships and/or badges that might "threaten" their online identity or self-presentation, which often led to non-disclosure of their location (Cramer et al., 2011; Lindqvist et al., 2011). For example, some users are concerned about game mechanics and gamification elements because they do not want to receive a badge that rewards an avid nightlife when colleagues are members of their Foursquare friend network. Additionally, game mechanics or community norms around gaming elements might restrict the visibility of certain types of mobility (Halegoua et al., 2012).

Motivations for location disclosure as well as non-disclosure via location-based social media have revealed interesting connections between check-ins, impression management, and presentation of self through these platforms. Some reiterated reasons for non- 
disclosure include: embarrassment, privacy concerns, professionalism and ethics, selfpresentation and not wanting to spam a social network with superfluous check-ins. Many of these concerns stem from the fact that Foursquare participants understand their checkins as part of their presentation of self online.

Ethnographic studies of Foursquare and other location-based social media use have noted participants' desire for self-quantification and cataloging of personal mobility patterns and physical presence over time. Foursquare users have noted that an archive of their checkins can be used as a memory aid (to remember where they've been, when, and with whom). Examining Foursquare check-ins, geocoded images, and annotations through the lens of the spatial self can add a qualitative framework for understanding individual patterns of mobility and sociality, and can highlight the online social contexts and practices within which location-announcement and documentation of personal mobility occur.

\section{Discussion}

We have proposed the spatial self as a term that categorizes a common cultural practice as well as a lens through which to study the growing number of geo-coded representations on locative and social media. Given the multiple and distinct depictions of the spatial self produced over a variety of platforms and within a variety of contexts and situations, this section identifies some of the unique opportunities the spatial self introduces for studying individuals, physical places, and social networks. More specifically, we consider how studying articulations of the spatial self via social media may yield valuable information pertaining to differential mobility patterns, polysemic meanings of place, and collective geographical patterns of social networks. 
The spatial self is an additional means through which people perform their online identity, and manage self-presentation on social networking sites and location-based social media. Just like other online representations of self, this form of representation carries many biases and limitations that researchers should take into consideration in their work. While there is still much to be learned about relationships between digital productions of mobility, selfpresentation, sociality, and place, these representations of physical activities should not be assumed to be accurate. The spatial self reminds researchers that these digital traces are produced and embedded within particular social contexts, significations systems, and subject to certain audiences and norms. If anything, they are more performative than precise. Therefore, the spatial self is a concept that urges methodological caution in analyzing location-based social media data, patterns of mobility iterated through social media, and location-announcement online.

However, these streams of data might provide researchers, technology developers, and urban planners with ways to access local insights and behaviors that were not previously available. The spatial self provides several unique aspects that can help researchers better understand collective and individual experiences and mobilities within urban space. In the following section we identify three categories of possible directions of study that set the spatial self apart from other forms of online representation of the self.

\section{Individual Users}

The spatial self offers a way to study the profile of individual social media users based on their physical activity. Instagram, Facebook, and Foursquare users exhibit and archive physical experiences alongside other markers of identity and employ the spatial self as a 
way to communicate where they are/were, what they're doing, as well as who they are. For example, during an interview with a food blogger (Halegoua, 2011) the interviewee noted that she would only check-in to restaurants that she personally recommends and that mesh with her tastes and sensibilities displayed on other online profiles and sites. This type of selection and curation of check-ins demonstrates one way social media users coordinate and incorporate the places displayed in their profile with other presentations of self. This aspect of the spatial self might speak more directly to social media researchers who are interested in analyzing ways in which people express themselves online and we encourage them to think about place and space as strategically chosen markers of identity and active agents in the process of online identity work.

The spatial self is a way to gain access to personal and collective memories, and a way to share and display these memories in order to connect with others. Through investigations of the spatial self on social media, researchers can gain access to diverse experiences of geography and mobility in relationship to class, race, gender, sexuality, and other markers of social identity; potentially disrupting hierarchical or hegemonic manners of understanding physical space and place. Moreover, the production of geocoded digital traces can reveal unique, selective daily patterns of mobility. Aggregating and visualizing data from social media platforms can provide researchers with new ways to study patterns of different users based on their historical activity throughout the city. As some users take pictures, tweet or checkin in many geographical locations, others' activity are confined to a small subset of the city's area revealing the unique patterns for each user. In the Phototrails project, Hochman and Manovich (2013) demonstrated how researchers can follow an individual user's online activity and visualize their pattern of mobility based on 
the type of places frequented (Figure 1). As the user's actions are highly curated and intended to present a certain depiction of the self, the type of places users select to checkinto or take photos of hold valuable meaning beyond their physical location.

\section{Physical Place}

Using large amounts of digital traces, researchers can study the character of specific physical places through new lenses. Utilizing users' historical actions on social media sets the foundation for dynamic narratives of a physical place. Examining the patterns that emerge from the users' demographics, comments, tips, photos and videos, we can infer how certain places function within particular social landscapes (Schwartz, forthcoming 2014).

The communicative act of cataloguing inner space (social distance or intimacy between people), outer space (physical distance between people in public space), and metaspace (which we expand to mean social space or social interactions that take place under certain conditions, contexts, or situations at given times) is present within all of the platforms discussed in this paper and can be used to signify important markers of identity (Humphreys, 2012). Studying expressions of the spatial self can teach us about the popularity and the patrons of a specific place. For example, vast work has been done in the field of computer science to identify landmarks and points of interests that have high visibility (most shared or tagged) on social media data (Kennedy and Naaman, 2008). Other studies utilized users' profile data such as home city and past activity to denote a place most frequented by tourists or locals (Fischer, 2011). 
Finally, the spatial self can help researchers uncover the polysemic meaning of a physical place. Places have multiple meanings to the same person or to different types of people, and these meanings may change over time. Representations of the spatial self can provide an entry point into accessing and reading these polyvocal interpretations and meanings of place. The contexts and situations under which these digital expressions of place are produced inform the image or check-in, and the motivation for location announcement. For example, we might be able to glean the polysemic interpretations of place by exploring the type of photos taken by different people at a certain place and how people are both creating and harnessing polysemic meanings and social constructions of place to represent themselves to others. Each photo tagged to a venue tells a different story about the individuals that took them, the moments and reasons they were taken, and the meaning of place.

\section{Social Networks}

Individual actions in physical places can help characterize and uncover collective geographic patterns of social networks. For example, when users check-in with their friends in a certain location they send cues to their online audience about the relations between the place and the social network that is attached to it. Studying online cues about geographic contexts of social networks can augment profiles created by urban planners in

order to represent different types of interactions between groups, political constituencies, demographic populations, tourists, etc within public space. An understanding of the spatial self can more robustly represent patterns of mobility for different groups of people and what these patterns might signify. For example, the Livehoods project offers a glance into 
the areas of the city that like-minded people visit (Cranshaw et al., 2012). The project shows how a series of bars, restaurants, parks, or shops may carry a strong connection for a certain group of people who include them in their social media profiles.

A related study that examined the profile pictures of bar patrons in Austin, Texas illustrated how Foursquare profile photos conveyed information about the character and connotations of specific venue based on impressions about the types of people who frequent these venues (Graham and Gosling, 2011). In a more recent work, researchers used geo-tagged tweets from the city of Los Angeles to understand the relationships between geographic regions and gang territories (Bora, 2013). This kind of work can trace homophily in regard to patterns of mobility and collective understandings of place, and make patterns of differential mobilities among certain groups more visible. Researchers can gain insight into how certain geopolitical inequalities are experienced, and uncover strategies for managing high or low mobility in both physical space and digital environments.

\section{Conclusion}

Digital expressions of the spatial self might help researchers highlight and understand new performances of self and re-inscriptions of the body in place and space. The digital traces that people produce through location-based social media networks may help inform researchers' understanding of urban experience and urban mobility, but should be recognized as performed or exhibited "traces" or fragments of larger articulations of physical presence and spatial realities. Geolocated posts, tweets, images, check-ins, and other forms of location announcement and artifacts of personal mobility are parts of larger narratives and performances of embodiment and experience of place. However, this 
geolocated information often masquerades as quantitative when, upon closer inspection, it is actually a mix of qualitative and quantitative data and should be treated as such.

GIS, GPS, maps, and digital technologies of navigation and monitoring in general are often connoted as accurate, precise, and are articulated with concepts like surveillance and security rather than performativity and flexibility. As Farman (2010) notes, by conceptualizing maps and cartographic practice as direct, accurate representations of reality and ignoring the subjectivity and social construction of cartographic representations, we also eschew important cultural interpretations of these visualizations. Because an image, text, or artifact is geocoded does not mean that it is a representation of objective "reality" or precise location. Instead, because these digital traces are geocoded representations of particular ways of being and representing the world, they require cultural interpretation in order to be unpacked and analyzed.

Moreover, there are privacy concerns (locational privacy and otherwise) that need to be considered when gathering user-generated geo-located data, especially since researchers and planners are not an intended audience for these expressions, and the isolation and recirculation of these digital productions was not consented to by participants. While we urge researchers to apply ethical caution in gathering and analyzing these digital traces of mobility and presence, we also urge methodological caution as well. As tools of analysis for user-generated geocoded data are still under development, we need to figure out ways to verify user-produced information (or volunteered geographic information), understand the biases in their production, and use these data sets without overestimating what they actually reflect. 
In this paper we have provided examples of how researchers can use location-based social media data to draw conclusions about people and places without exaggerating what these digital traces illustrate, practicing apophenia in regard to vast amounts of data (boyd and Crawford 2011), or mistaking qualitative data for quantitative. To think about Instagram images, Facebook or Foursquare check-ins as representing the places that are "most important" to participants or as the "places that matter" is inaccurate. We need to understand not only the motivations for producing these images and check-ins but also what they mean to the participants and their audiences - how they are being used as a form of self-presentation as well as (re)productive practices of experience and reception of urban space.

Performativity within social media and the expression of place as linked to selfpresentation within social networking sites is deserving of further study. We suggest that the spatial self is a lens through which to read some of the texts produced over social media and to understand the biases and limitations of the geographic and temporal precision of this data. We also argue that it is important for researchers to employ both qualitative and quantitative methods for analyzing user generated geo-located content. Expressions of the spatial self are not always precise in terms of calculating actual mobility or physical presence, but they are precisely calculated, choreographed articulations of space and the self based on identity production and self expression.

\section{Acknowledgments}

The authors made equal contributions to this paper. 


\section{BIBLIOGRAPHY}

Alibrandi M, Thompson A and Hagevik R (2000) Documenting a culture. ArcNews 22 (3):

27.

Barkhuus L, Brown B, Bell M, Sherwood S, Hall M, Chalmers M (2008) From Awareness to Repartee: Sharing Location Within Social Groups. In: Proc. CHI`08, ACM Press. pp. 497-506.

Bentley F, Cramer H, Basapur S and Hamilton H (2012) Drawing the City: Differing Perceptions of the Urban Environment. In: CHI 2012, Austin, Texas, USA, May 5-10, 2012.

Bora N, Zaytsev V, Chang Y, and Maheswaran R (2013) Gang Networks, Neighborhoods, and Holidays: Spatiotemporal Patterns in Social Media. In: 2013 ASE/IEEE International Conference on Social Computing Projects, September 8-14, 2013, Washington DC, USA. boyd d (2002) Faceted Id/entity: Managing Representation in a Digital World. (MA thesis). boyd d and Crawford K (2011) Six Provocations for Big Data. Paper Presented at A Decade in Internet Time: Symposium on the Dynamics of the Internet and Society, Oxford Internet Institute, 21 September, 2011.

Brown B, Taylor A, Izadi S, Sellen A and Kay J (2007) Locating Family Values: A Field Trial of the Whereabouts Clock. In: Proc. of UbiComp 2007. Insbruck, Austria. Springer, pp. 354-371. 
Butler J (1988) Performative Acts and Gender Constitution: An Essay in Phenomenology and Feminist Theory. Theatre Journal, (40) 4, 519-531.

Cramer H, Rost M, Holmquist LE (2011) Performing a Check-in: Emerging Practices, Norms and 'Conflicts' in Location-Sharing Using Foursquare. In: MobileHCI 2011, Aug 30-Sept 2, 2011, Stockholm, Sweden.

Crandall D, Backstrom L, Huttenlocher, D, and Kleinberg J (2009) Mapping the World's Photos. In: proc. 18th International WWW Conference. Madrid, Spain, April 20-24, 2009.

Cranshaw J, Schwartz R, Hong J, Sadeh N (2012) The Livehoods Project: Utilizing Social Media to Understand the Dynamics of a City. In: proc. of the 6th International AAAI Conference on Weblogs and Social Media (ICWSM-12), Dublin, Ireland, June 2012.

Cox C (2011) Making It Easier to Share With Who You Want. In: The Facebook Blog. Available at: https://blog.facebook.com/blog.php?post=10150251867797131 (accessed 25 September 2013)

de Souza e Silva A and Frith J (2012) Mobile Interfaces in Public Spaces: Locational Privacy, Control, and Urban Sociality. New York: Routledge.

Doersch C, Singh S, Abhinav G, Josef S, and Efros A (2012) What Makes Paris Look like Paris? In: ACM Transactions on Graphics (SIGGRAPH 2012), August 2012, 31(3).

Ellison NB and boyd d (2013) Sociality through Social Network Sites. In: Dutton WH (ed) The Oxford Handbook of Internet Studies. Oxford: Oxford University Press, pp. 151-172. 
Farman J (2010) Mapping the Digital Empire: Google Earth and the Process of Postmodern Cartography. New Media \& Society 12(6): 869-888.

Farman J (2012) Mobile Interface Theory: Embodied Space and Locative Media. New York: Routledge.

Fischer E (2010) The geotaggers' world atlas. Available at: http://www.flickr.com/photos/walkingsf/sets/72157623971287575/ (accessed 25 September 2013)

Frith J (2012) Constructing Location, One Checkin at a Time: Examining the Practices of Foursquare Users. (Doctoral Dissertation).

Frith J (2013) Turning Life into a Game: Foursquare, gamification, and personal mobility. Mobile Media \& Communication 1(2): 248-262.

Foursquare (2013) About. Available at: https://foursquare.com/about/ (accessed 25 September 2013)

Goodings L, Locke A and Brown SD (2007) Social networking technology: place and identity in mediated communities. Journal of Community \& Applied Social Psychology. 17(6): 463-476.

Gordon E and de Souza e Silva A (2011) Net Locality: why location matters in a networked world. Malden: Wiley-Blackwell. 
Graham L and Gosling S (2011) Can the ambiance of a place be determined by the user profiles of the people who visit it? In: ICWSM-11, The AAAI Press. pp. 145-152.

Gregson N and Rose G (2000) Taking Butler elsewhere: performativities, spatialities, and subjectivities. Environment and Planning D: Society and Space 2000(18): 433-452.

Grosz E (1992) Bodies-cities. In: Colomina B (ed) Sexuality and space. New York: Princeton Architectural Press, pp. 241-53.

Halegoua GR (2011) Foursquare Checkins in Claimed Venues. Unpublished raw data.

Halegoua GR, Leavitt A, and Gray ML (2012) Jumping for Fun?: Negotiating Mobility and the Geopolitics of Foursquare. Paper presented at the annual meeting of the International Communication Association, Phoenix, AZ March 16-18.

Hjorth L (2013) Relocating the mobile : A case study of locative media in Seoul, South Korea. Convergence 2013. (19) 237.

Hjorth L, Wilken R and Gu K (2012) Ambient intimacy: a case study of the iphone, presence, and location-based social networking in Shanghai, China. In: Hjorth L, Burgess J and Richardson I (eds) Studying Mobile Media: Cultural Technologies, Mobile Communication, and the iPhone. London/New York: Routledge, pp. 43-62.

Hochman N and Manovich L (2013) Zooming into an Instagram City: Reading the local through social media. First Monday. 18(7). (accessed 25 September 2013) http://www.firstmonday.dk/ojs/index.php/fm/article/view/4711/3698 
Hochman N and Schwartz R (2012) Visualizing Instagram: Tracing Cultural Visual Rhythms. Workshop on Social Media Visualization in conjunction ICWSM-12. Dublin, Ireland, June 2012.

Hogan B (2010) The Presentation of Self in the Age of Social Media: Distinguishing Performances and Exhibitions Online. Bulletin of Science, Technology, and Society 30(6): 377-386.

Humphreys L (2007) Mobile Social Networks and Spatial Practice: A case study of Dodgeball. Journal of Computer Mediated Communication. 13(1): article 17.

Humphreys L (2012) Connecting, Coordinating, Cataloguing: Communicative Practices on Mobile Social Networks, Journal of Broadcasting \& Electronic Media, 56(4): 494-510.

Instagram (2013) Instagram Today: 150 Million People. In: Instagram Blog. Available at: http://blog.instagram.com/post/60694542173/150-million (accessed 25 September 2013)

Kennedy LS and Naaman M (2008) Generating diverse and representative image search results for landmarks. In: Proc. of $W W W^{\prime}$ '08. ACM, New York, NY, USA, 297-306.

Kwan MP (2002) Feminist Visualization: Re-Envisioning GIS as a Method in Feminist Geographic Research. In: Annals of the Association of American Geographers, 92(4): 645661.

Lindqvist J, Cranshaw J, Wiese J, Hong J, Zimmerman J (2011) I'm the Mayor of My House: Examining why people use Foursquare - a social driven Location Sharing Application. In CHI 2011, Vancouver, Canada. May 7-12, 2011. 
Mendelson A and Papacharissi Z (2010) Look at Us: Collective Narcissism in College Student Facebook Photo Galleries. In: Papacharissi Z (ed) The Networked Self: Identity, Community and Culture on Social Network Sites. Routledge.

Milne E (2010) Letters, Postcards, Email: Technologies of Presence. New York: Routledge.

Moore J (2012) Visualizing Activity on Facebook. In: Facebook Data Science Notes. Available at: https://www.facebook.com/notes/facebook-data-science/visualizingactivity-on-facebook/10150884743158859 (accessed 25 September 2013)

Papacharissi Z (2011) Conclusion: A Networked Self. In: Papacharissi Z (ed) The Networked Self: Identity, Community and Culture on Social Network Sites. Routledge.

Patil S, Norcie G, Kapadia A, Lee A (2012) Check out Where I Am!: location-sharing motivations, preferences, and practices. In: proc. of CHI EA '12. pp. 1997-2002

Schwartz R (forthcoming, 2014) Online Place attachment: Exploring Technological Ties to Physical Places. In: de Souza e Silva A and Sheller M (eds) Location, Mobile Technologies and Mobility ed. New York: Routledge.

Schwartz R and Hochman N (forthcoming, 2014) The Social Media Life of Public Spaces: Reading Places Through the Lens of Geo-Tagged Data. In: Wilken R and Goggin G (eds), Locative Media. New York: Routledge.

Sheller M (2013) Mobile Conviviality. In: Flow, 17.09(17) Available at: http://flowtv.org/2013/03/mobile-conviviality/(accessed 25 September 2013) 
Sheller M (2012) Mobile Mediality. In: Flow 17(1) Available at: http://flowtv.org/2012/11/mobile-mediality/(accessed 25 September 2013)

Sutko DM and de Souza e Silva A (2011) Location-aware mobile media and urban sociability. New Media \& Society, 13(5): 807-823.

Van House NA (2009) Collocated photo sharing, story-telling, and the performance of self. International Journal of Human-Computer Studies. 67: 1073-1086.

Van Zoonen L (2013) From identity to identification: Fixating the fragmented self. Media, Culture and Society 35(1): 44-51.

Walker AL and Moulton RK (1989) Photo Albums: Images of Time and Reflections of Self. Qualitative Sociology 12(2): 155-182.

Wilson E (1992) The Sphinx in the City: Urban Life, the Control of Disorder, and Women. Berkeley: University of California Press. 


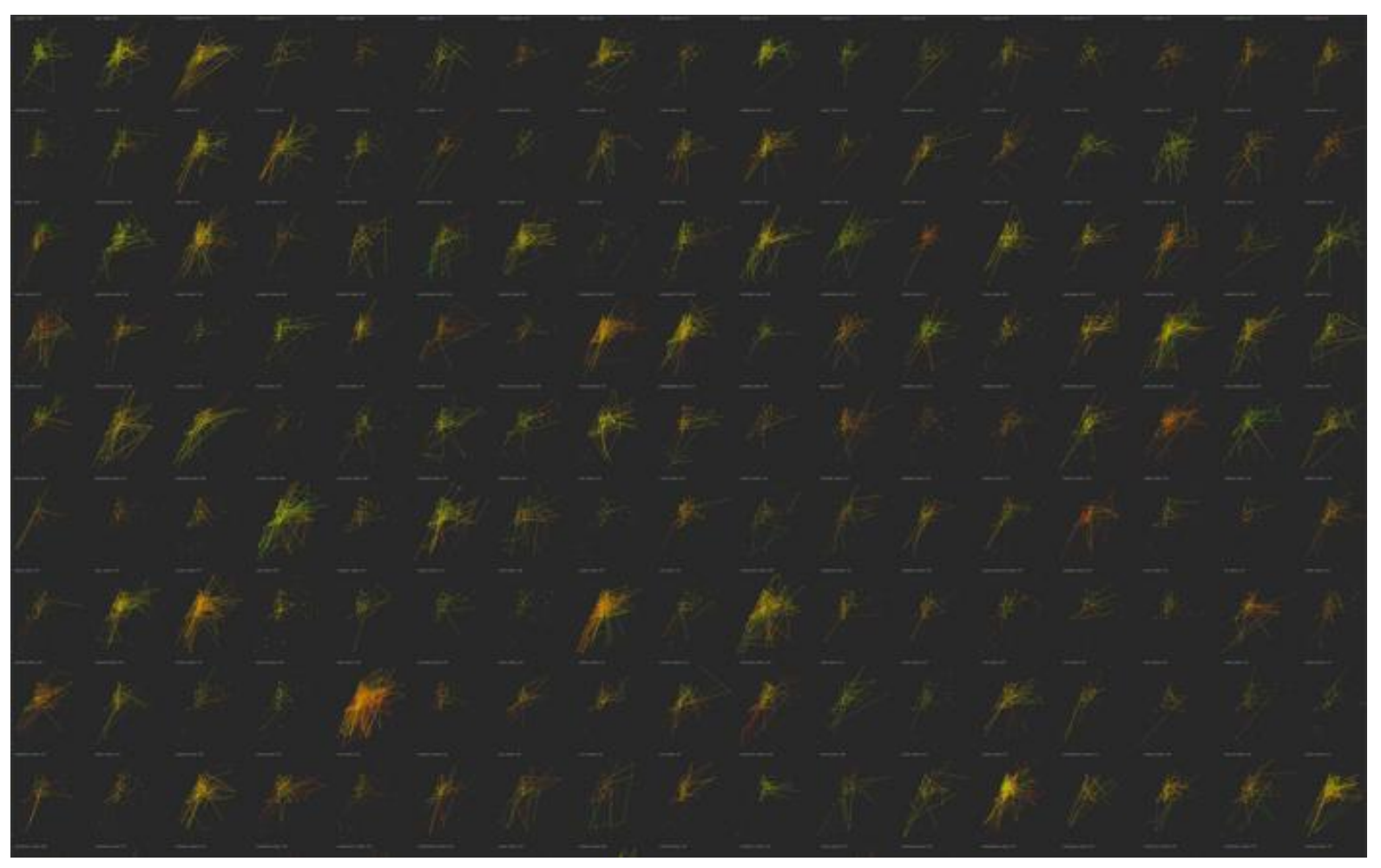

Figure 1: Matrix plot comparing activity of 289 most active Instagram users in Tel Aviv, Israel. Available at: http://phototrails.net/lines-users-matrix/ accessed 25 September 2013. 


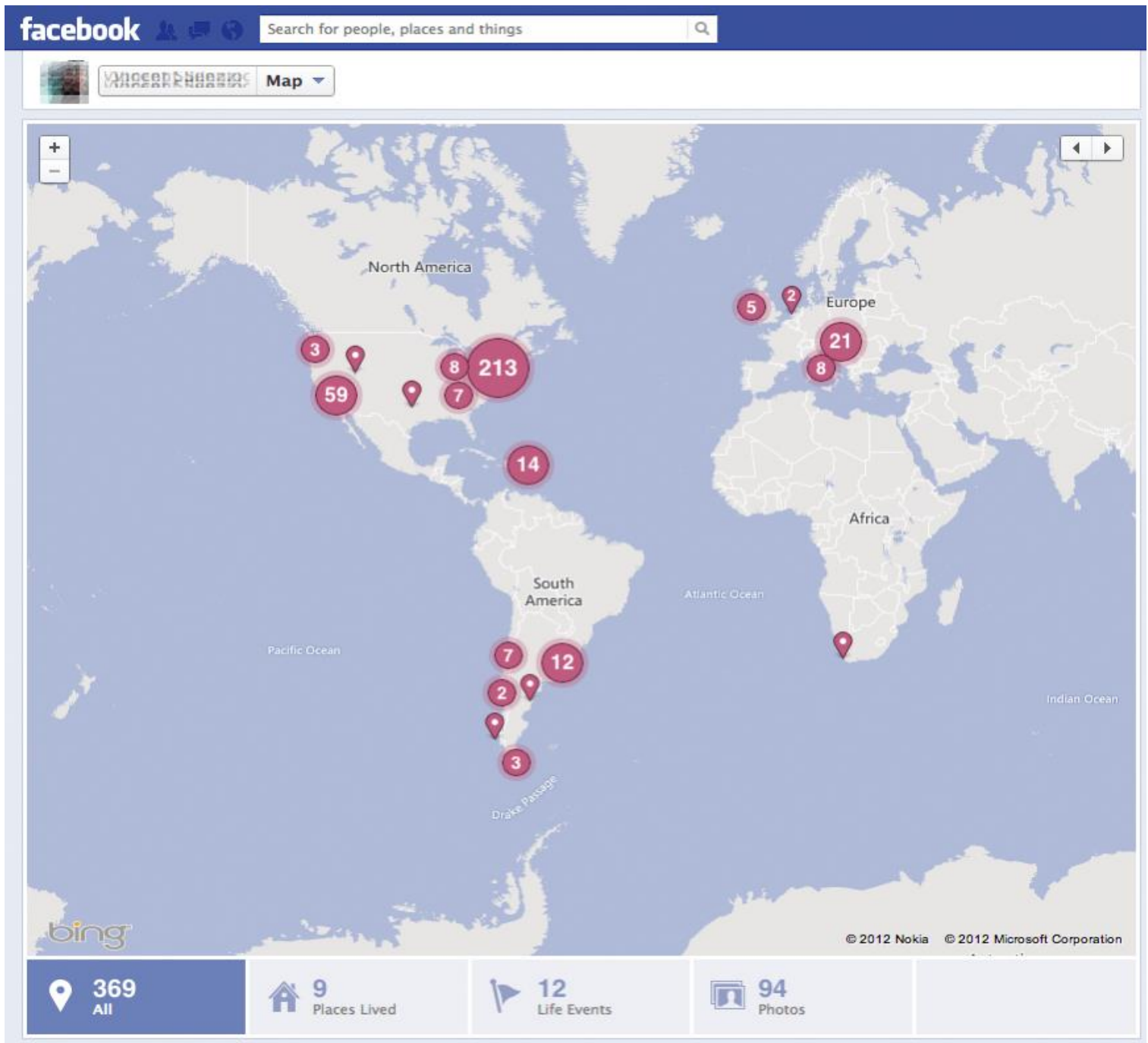

Figure 2: A user profile map on Facebook 